\title{
Evaluating Provider Advice and Women's Beliefs on Total Weight Gain During Pregnancy
}

\author{
Nkiruka V. Arinze - Sharon M. Karp • \\ Sabina B. Gesell
}

Published online: 4 February 2015

(c) The Author(s) 2015. This article is published with open access at Springerlink.com

\begin{abstract}
Excessive gestational weight gain (GWG) is associated with complications for both mother and child. Minority women are at increased risk for excessive GWG, yet are underrepresented in published weight control interventions. To inform future interventions, we examined the prevalence and accuracy of provider advice and its association with personal beliefs about necessary maternal weight gain among predominantly Latina pregnant women. Secondary analysis examining baseline data $(\mathrm{N}=123)$ from a healthy lifestyle randomized controlled trial conducted in and urban area of the South East. Only $23.6 \%$ of women reported being told how much weight to gain during pregnancy; although $58.6 \%$ received advice that met Institute of Medicine recommendations. Concordance of mothers' personal weight gain target with clinical recommendations varied by mothers' pre-pregnancy weight status $\left[\chi_{(4)}^{2}=9.781, p=0.044\right]$. Findings suggest the need for prenatal providers of low-income, minority women to engage patients in shaping healthy weight gain targets as a precursor to preventing excessive GWG and its complications.
\end{abstract}

N. V. Arinze

Vanderbilt University School of Medicine, Nashville, TN, USA

\section{S. M. Karp}

Schools of Nursing and Medicine (Pediatrics), Vanderbilt University, Nashville, TN, USA

\section{S. B. Gesell ( $₫)$}

Division of Public Health Sciences, Department of Social Sciences and Health Policy, Wake Forest School of Medicine, Maya Angelou Center for Health Equity, Medical Center Boulevard, Winston-Salem, NC 27157, USA

e-mail: sgesell@wakehealth.edu
Keywords Gestational weight gain · Hispanic - Obesity · Health disparities

\section{Introduction}

In 2009, the Institute of Medicine (IOM) revised its guidelines for appropriate weight gain during pregnancy, taking into account the growing prevalence of obesity in women of childbearing age [1]. (Table 1) Over $40 \%$ of pregnant women exceed the IOM recommendations for gestational weight gain (GWG), with overweight and obese women at increased risk [2]. Excessive weight gain during pregnancy is associated with complications in delivery [3], increased postpartum weight retention [4], persistent obesity [4], increased BMI in offspring in childhood, adolescence and adulthood [5], and longer maternal hospital stay after labor and delivery [5].

Actual weight gain during pregnancy is strongly influenced by provider recommendation [6,7]. Evidence shows that women's actual weight gain during pregnancy is strongly influenced by personal beliefs and healthcare providers' advice [6,7]. When women receive weight gain advice that is inconsistent with IOM recommendations (i.e., above or below), they are 3.6 times more likely to gain more or less than IOM recommendations, respectively [7]. Women whose personal weight gain targets are below IOM recommendations are five times more likely to gain less than recommended, and women with targets above the recommendations are six times more likely to gain more than recommended [7].

There is limited data about the beliefs of Latinas on GWG even though the problem of excessive weight gain during pregnancy is particularly important for this group which now comprises $20 \%$ of new mothers in the US [1]. 
Table 1 Clinical recommendations for cumulative gestational weight gain by pre-pregnancy BMI for mothers of singletons and twins at gestational ages 37-42 weeks (IOM, 2009)

\begin{tabular}{llc}
\hline Prepregnancy BMI & \multicolumn{2}{l}{$\begin{array}{l}\text { Recommended range of } \\
\text { Cumulative weight gain (lbs) }\end{array}$} \\
\cline { 2 - 3 } & Singleton & Twins \\
\hline Underweight $\left(<18.5 \mathrm{~kg} / \mathrm{m}^{2}\right)$ & $28-40$ & - \\
Normal $\left(18.5-24.9 \mathrm{~kg} / \mathrm{m}^{2}\right)$ & $25-35$ & $37-54$ \\
Overweight $\left(25.0-29.9 \mathrm{~kg} / \mathrm{m}^{2}\right)$ & $15-25$ & $31-50$ \\
Obese $\left(\geq 30.0 \mathrm{~kg} / \mathrm{m}^{2}\right)$ & $11-20$ & $24-42$ \\
\hline
\end{tabular}

At $65.4 \%$, the prevalence for overweight and obesity in Latinas aged 20-39 years is higher than the national prevalence for all women in that age group [8]. This increased rate of overweight and obesity puts Latinas at increased risk for excessive GWG. The purpose of this paper is to examine the prevalence and accuracy of provider advice on maternal weight gain and its association with personal beliefs about necessary maternal weight gain within a sample of predominantly Latina pregnant women who received prenatal care in their dominant language.

\section{Methods}

\section{Study Design and Participants}

We examined baseline data $(\mathrm{N}=123)$ from a randomized controlled trial, Madre Sana, Bebé Sano (Healthy Mother, Healthy Baby), designed to prevent excessive GWG. IRB approval was obtained from Vanderbilt and Wake Forest Universities.

\section{Eligibility Criteria}

Eligibility criteria included Spanish or English speaking women, $\geq 16$ years, 10-28 weeks gestation, receiving prenatal care, planning to stay in the area for the full pregnancy, and willing to authorize release of medical information for the purpose of data abstraction.

\section{Recruitment}

Recruitment and enrollment took place at various obstetric clinics in an urban area of the South East from JanuaryApril 2011.

\section{Consent/Assent Process}

Eligible women were informed of the study and, if interested, consented in their language of preference (Spanish/ English).

\section{Measures}

The study questionnaire was administered by trained study personnel in Spanish or English in participants' homes.

\section{Pre-Pregnancy Body Mass Index (BMI)}

Self-reported pre-pregnancy weight and measured height collected at baseline were used to calculate pre-pregnancy BMI [9].

\section{Provider Advice on Gestational Weight Gain and Weight} Gain Target

Women were asked (1) "Has your health professional told you how many pounds (kilos) you should gain during this pregnancy?" (2) "How many pounds (kilos) did your health professional say you should gain from the beginning to the end of this pregnancy?" and (3) "How many pounds (kilos) do you think you should gain from the beginning to the end of this pregnancy?" Responses were compared to the 2009 IOM recommendations.

\section{Sociodemographics}

The demographic variables used in this study included maternal age, country of origin, ethnicity, education, language preference, years spent in the US, parity, use of tobacco, alcohol and prenatal vitamins during pregnancy, employment, and participation in the Special Supplemental Nutrition Program for Women, Infants and Children (WIC).

\section{Statistical Analysis}

Chi- squared tests were used to compare frequency distributions. $P<0.05$ was considered significant.

\section{Results}

Sample Demographics

The mean age of respondents $(\mathrm{N}=123)$ was 26.3 years (SD 5.9). Women classified themselves as Latina (78 \%), African-American (14\%), Caucasian (4\%), or other (4\%). Approximately three-quarters of the women were immigrants (75\%), primarily from Mexico and Honduras. All women received prenatal care in their dominant language (Spanish/English) (Table 2). 
Table 2 Sample demographics $(\mathrm{N}=123)$

\begin{tabular}{|c|c|}
\hline & $\mathrm{N}(\%)$ \\
\hline \multicolumn{2}{|l|}{ Maternal age (years) } \\
\hline$<18$ & $4(2.8)$ \\
\hline $18-24$ & $60(41.7)$ \\
\hline $25-30$ & $42(29.2)$ \\
\hline$>30$ & $38(26.4)$ \\
\hline \multicolumn{2}{|l|}{ Pre-pregnancy BMI } \\
\hline Under & $0(0)$ \\
\hline Normal & $48(39.0)$ \\
\hline Overweight & $41(33.3)$ \\
\hline Obese & $34(27.6)$ \\
\hline \multicolumn{2}{|l|}{ Country of origin } \\
\hline United States & $30(24.4)$ \\
\hline Mexico & $59(48.0)$ \\
\hline Honduras & $13(10.6)$ \\
\hline Other Latin Am. country & $16(13.0)$ \\
\hline African country & $3(2.4)$ \\
\hline Other country & $2(1.6)$ \\
\hline \multicolumn{2}{|l|}{ Highest education level } \\
\hline Eighth grade or below & $26(21.1)$ \\
\hline Some HS, no diploma & $51(41.5)$ \\
\hline HS diploma/GED & $28(22.7)$ \\
\hline Some college, vocational/technical degree & $13(10.6)$ \\
\hline Bachelor's degree or higher & $5(4.1)$ \\
\hline \multicolumn{2}{|l|}{ Language of preference } \\
\hline English & $29(23.6)$ \\
\hline Spanish & $85(69.1)$ \\
\hline English and Spanish & $9(7.3)$ \\
\hline \multicolumn{2}{|l|}{ WIC } \\
\hline No & $48(39.3)$ \\
\hline Yes & $74(60.7)$ \\
\hline \multicolumn{2}{|l|}{ Expecting Twins } \\
\hline No & $121(98.4)$ \\
\hline Yes & $2(1.6)$ \\
\hline \multicolumn{2}{|l|}{ Previous pregnancies } \\
\hline 0 & $42(34.1)$ \\
\hline 1 & $34(27.6)$ \\
\hline 2 & $24(19.5)$ \\
\hline 3 & $16(13.0)$ \\
\hline 4 & $4(3.3)$ \\
\hline 5 & $2(1.6)$ \\
\hline 6 & $0(0)$ \\
\hline 7 & $1(0.8)$ \\
\hline \multicolumn{2}{|l|}{ Smoked after pregnancy was confirmed } \\
\hline No & $110(90.2)$ \\
\hline Yes & $12(9.8)$ \\
\hline \multicolumn{2}{|c|}{ Consumed alcohol after pregnancy was confirmed } \\
\hline No & $111(91.0)$ \\
\hline Yes & $11(9)$ \\
\hline
\end{tabular}

Table 2 continued

\begin{tabular}{lc}
\hline & $\mathrm{N}(\%)$ \\
\hline Taking prenatal vitamins & $9(7.3)$ \\
No & $114(92.7)$ \\
Yes & \\
Currently employed & $17(13.9)$ \\
No, by choice & $56(45.9)$ \\
No, not by choice & $10(8.2)$ \\
Yes, but with an irregular schedule & $18(14.8)$ \\
Yes, part time & $21(17.2)$ \\
Yes, full time & \\
\hline
\end{tabular}

Provider Advice on Gestational Weight Gain

Although all of the women had at least one prenatal appointment before completing the baseline survey, only $24 \%$ reported that their healthcare provider told them how much weight to gain during their pregnancy. Receiving advice did not vary by pre-pregnancy BMI $\left[\chi_{(2)}^{2}=0.421\right.$, $p=0.810]$.

Of those who reported receiving advice on GWG, $59 \%$ (17/29) reported receiving advice that fell within and $31 \%$ (9/29) that was above the IOM recommendations, and $10 \%(3 / 29)$ could not remember the advice. The concordance of providers' weight gain advice with IOM recommendations did not vary by mothers' pre-pregnancy BMI $\left[\chi_{(2)}^{2}=2.382, p=0.304\right]$.

\section{Personal Gestational Weight Gain Target}

When asked how much weight they thought they should gain during their pregnancy, $25 \%$ of participants had personal weight gain targets below the IOM target range $49 \%$ had targets within the recommended range $15 \%$ had weight gain targets above the recommended range and $11 \%$ did not know how much weight to gain. The concordance of mothers' personal weight gain target with IOM recommendations varied by their pre-pregnancy weight status: Normal weight mothers were more likely to have low weight gain targets, whereas overweight and obese women were more likely to have high weight gain targets (Table 3).

The concordance of mothers' weight gain targets with IOM recommendations also varied by receipt of professional advice. Those receiving advice were more likely to have accurate personal weight gain targets, whereas those women who did not receive professional advice were more likely to have low or high personal weight gain targets (Table 4).The concordance of mothers' weight gain targets with IOM recommendations did not vary by language 
Table 3 Association of mother's personal gestational weight gain targets and their pre-pregnancy weight category

\begin{tabular}{|c|c|c|c|c|c|}
\hline & & \multicolumn{3}{|c|}{ Pre-pregnancy BMI } & \multirow[b]{2}{*}{ Total } \\
\hline & & Normal & Overweight & Obese & \\
\hline \multirow{4}{*}{$\begin{array}{l}\text { Accuracy of mother's } \\
\text { weight gain target }\end{array}$} & Under IOM rec & $18(40.9 \%)$ & $6(16.7 \%)$ & $7(23.26 \%)$ & $31(28.2 \%)$ \\
\hline & Within IOM rec & $23(52.3 \%)$ & $23(63.9 \%)$ & $15(50 \%)$ & $61(55.5 \%)$ \\
\hline & Above IOM rec & $3(6.8 \%)$ & $7(19.4 \%)$ & $8(26.7 \%)$ & $18(16.4 \%)$ \\
\hline & & $44(100 \%)$ & $36(100 \%)$ & $30(100 \%)$ & $110(100 \%)$ \\
\hline
\end{tabular}

Only 110 of the 123 women in the sample responded to the survey question about personal weight gain target

$\chi^{2}(4)=9.781, p=0.044$

Table 4 Association of mother's personal gestational weight gain targets and their provider giving advice on appropriate weight gain

$\chi^{2}(2)=7.519, p=0.023$

\begin{tabular}{lllrr}
\hline & & \multicolumn{2}{l}{ Professional advice on weight gain received } & \\
\cline { 3 - 4 } & & No & Yes & Total \\
\hline Accuracy of mother's & Under IOM rec & $28(34.1 \%)$ & $3(11.1 \%)$ & $31(28.4 \%)$ \\
weight gain target & Within IOM rec & $40(48.8 \%)$ & $21(77.8 \%)$ & $61(56.0 \%)$ \\
& Above IOM rec & $15(18.1 \%)$ & $3(11.1 \%)$ & $17(15.6 \%)$ \\
& & $83(100 \%)$ & $27(100 \%)$ & $110(100 \%)$ \\
\hline
\end{tabular}

preference, years in the US, maternal education, or WIC status.

\section{Discussion}

Despite the attention garnered by the 2009 revision of the IOM's guidelines for weight gain during pregnancy, many of the low-income, minority women in this sample did not receive information about appropriate GWG. This vulnerable population is already at increased risk of excessive GWG and the concomitant adverse effects on mother and child.

Provider advice is key in helping women meet appropriate GWG targets [6]. While less than a quarter of women in our study reported receiving any information on weight gain, those who did were more likely to have target weights within clinical recommendations. Furthermore, most participants who reported receiving advice on GWG got recommendations within the current IOM standards.

Within our sample, provider advice and accuracy did not vary based on women's pre-pregnancy BMI. Yet similar to other reports in predominantly white women [6], we found that pre-pregnancy BMI is strongly associated with Latina women's target weight gain. Together, these findings suggest that providers are as comfortable discussing weight gain restrictions with overweight and obese women as they are with normal weight women, but that overweight and obese women still have weight gain targets in excess of clinical guidelines. Providers may need to re-emphasize their recommendations with overweight and obese patients to help align their personal weight gain targets with current clinical recommendations.

In the few women in our sample $(<25 \%)$ who reported receiving provider advice on appropriate weight gain, $31 \%$ received recommendations in excess of current clinical guidelines. Both the lack of receipt of clinical guidance and the recollection of inaccurate information observed in this study are of concern because receipt of provider advice has been shown in prior work to be the most important predictor of a woman's weight gain target [6].

Women who have a weight gain target that is concordant with IOM recommendation are less likely to have excessive weight gain [4]. In our study, normal weight mothers were more likely to have low weight gain targets, whereas overweight and obese women were more likely to have high weight gain targets. This is of concern because excessive weight gain is associated with postpartum weight retention and persistent maternal obesity [4].

Accuracy of women's weight gain target did not vary by acculturation (language preference, years in the US). Our study compared women who had been in the US for fewer or more than 5 years. Other work has shown that generational acculturation was positively associated with excessive GWG [10]. While low maternal education has been associated with higher rates of excessive weight gain [2], our study did not find any significant effect of maternal education on weight gain target. 
Understanding beliefs about appropriate weight gain during pregnancy is crucial for intervention planning. The strength of this study is its focus on minority women who are underrepresented in published GWG interventions yet carry increased burden of gaining excessively during pregnancy. Three-quarters of participants reported not receiving advice on appropriate weight gain during early prenatal care visits. However, those who did receive advice were more likely to have personal weight gain targets in line with current clinical recommendations. These data suggest that prenatal care providers of low-income, minority women in particular should make healthy maternal weight gain targets a priority in their care to prevent excessive weight gain during pregnancy and the associated complications.

Acknowledgments The project described was supported by Award Number K23HD064700 (Gesell) from the Eunice Kennedy Shriver National Institute of Child Health and Development; and Project Diabetes Grant (Contract \# GR-11-34418) from the State of Tennessee (Gesell). NA was supported by AmeriCorps STATE Grant (Coalition for Healthy Aging), the Vanderbilt University School of Medicine, and the National Institute of Diabetes and Digestive and Kidney Diseases Grant Number 5T35DK007383-32. Award Number UL1TRR24975, which is now UL1TR000445 at the National Center for Advancing Translational Sciences supported the REDCap database. The content is solely the responsibility of the authors and does not necessarily represent the official views of the funding agencies. The authors thank Nashville Parks and Recreation for collaboration in this community-engaged research project. The authors thank Karen Potvin Klein (Office of Research, Wake Forest University Health Sciences) for her editorial comments.

Conflict of interest The authors declare that they have no competing interests.

Open Access This article is distributed under the terms of the Creative Commons Attribution License which permits any use, distribution, and reproduction in any medium, provided the original author(s) and the source are credited.

\section{References}

1. Institute of Medicine NRC. Weight gain during pregnancy: reexamining the guidelines. Washington: National Academy of Sciences; 2009.

2. Chu SY, Callaghan WM, Bish CL, D'Angelo D. Gestational weight gain by body mass index among US women delivering live births, 2004-2005: fueling future obesity. Am J Obstet Gynecol. 2009;200(3):271e1-7.

3. Stotland NE, Cheng YW, Hopkins LM, Caughey AB. Gestational weight gain and adverse neonatal outcome among term infants. Obstet Gynecol. 2006;108:635-43.

4. Nehring I, Schmoll S, Beyerlein A, Hauner H, von Kries R. Gestational weight gain and long-term postpartum weight retention: a meta-analysis. Am J Clin Nutr. 2011;94(5):1225-31.

5. Mamun AA, O'Callaghan M, Callaway L, Williams G, Najman J, Lawlor DA. Associations of gestational weight gain with offspring body mass index and blood pressure at 21 years of age: evidence from a birth cohort study. Circulation. 2009;119(13): 1720-7.

6. Stotland NE, Haas JS, Brawarsky P, Jackson RA, Fuentes-Afflick E, Escobar GJ. Body mass index, provider advice, and target gestational weight gain. Obstet Gynecol. 2005;105(3):633-8.

7. Cogswell ME, Scanlon KS, Fein SB, Schieve LA. Medically advised, mother's personal target, and actual weight gain during pregnancy. Obstet Gynecol. 1999;94(4):616-22.

8. Flegal KM, Carroll MD, Kit BK, Ogden CL. Prevalence of obesity and trends in the distribution of body mass index among US adults, 1999-2010. JAMA. 2012;307(5):491-7.

9. Centers for Disease Control and Prevention. Adult BMI calculator: English. 2011 (cited 2014 May); http://www.cdc.gov/heal thyweight/assessing/bmi/adult_BMI/english_bmi_calculator/bmi_ calculator.html.

10. Chasan-Taber L, Schmidt M, Pekow P, Sternfeld B, Solomon C, Markenson G. Predictors of excessive and inadequate gestational weight gain in Hispanic women. Obesity. 2008;16(7):1657-66. 